\title{
Crystallization of $\mathrm{Fe}_{82} \mathrm{Si}_{2} \mathrm{~B}_{16}$ and $\mathrm{Fe}_{82} \mathrm{Si}_{4} \mathrm{~B}_{14}$ metallic glasses upon isothermal and non-isothermal annealing
}

\author{
A.P. Shpak ${ }^{1}$, A.G. Il'inskii ${ }^{1}$, A.V. Marunyak ${ }^{1}$, O.I. Slukhovskyy ${ }^{1}$, Yu.V. Lepeeva ${ }^{1}$, A. Dekhtyar ${ }^{1}$, I. Kaban $^{2, a}$, \\ N. Mattern ${ }^{2}$, and J. Eckert ${ }^{2,3}$ \\ ${ }^{1}$ G.V. Kurdymov Institute for Metal Physics, National Academy of Sciences of Ukraine, 36 Vernadsky Str., \\ 03142 Kyiv, Ukraine \\ ${ }^{2}$ IFW Dresden, Institute for Complex Materials, P.O.B. 270116, D-01171 Dresden, Germany \\ ${ }^{3}$ TU Dresden, Institute of Materials Science, D-01062 Dresden, Germany
}

\begin{abstract}
Crystallization of $\mathrm{Fe}_{82} \mathrm{Si}_{2} \mathrm{~B}_{16}$ and $\mathrm{Fe}_{82} \mathrm{Si}_{4} \mathrm{~B}_{14}$ metallic glasses upon heat treatment has been studied. The amorphous ribbons have been isothermally annealed at different temperatures $(673,693,733$ and $743 \mathrm{~K})$ and for various times (from 15 min to 78 hours). Phase compositions and the sequence of their appearance in dependence on the annealing temperature and time have been established.
\end{abstract}

\section{Introduction}

Metallic glasses and nanocrystalline materials based on Fe-Si-B ternary alloys are soft magnetic materials characterized by high permeability and low energy loss. They have successfully substituted crystalline ferromagnetic materials in magnetic cores of transformers, chokes and other inductive devices [1,2]. Their magnetic properties are mainly determined by the nanocrystalline structure obtained by controlled heat treatment via crystallization of amorphous ribbons. Therefore, knowledge of the crystallization sequence and the ranges of thermal stability is extremely important for practical application of these alloys.

Crystallization of Fe-Si-B metallic glasses upon annealing has been extensively studied already [3-12]. In recent works [10-12] three amorphous alloys within a narrow composition range were investigated $\left(\mathrm{Fe}_{82} \mathrm{Si}_{2} \mathrm{~B}_{16}\right.$, $\mathrm{Fe}_{80} \mathrm{Si}_{6} \mathrm{~B}_{14}$, and $\mathrm{Fe}_{77} \mathrm{Si}_{8} \mathrm{~B}_{15}$ ). The $\mathrm{Fe}_{82} \mathrm{Si}_{2} \mathrm{~B}_{16}$ metallic glass was found to crystallize in two stages. It was suggested that at first, b.c.c. phases of $\alpha-\mathrm{Fe}$ and probably $\mathrm{Fe}_{3} \mathrm{Si}$ appear together with the metastable $\mathrm{Fe}_{3} \mathrm{~B}$ phase; then, the metastable Fe-boride transforms into the stable $\mathrm{Fe}_{2} \mathrm{~B}$ and $\alpha$-Fe phases. On the other hand, glasses with lower boron content $\left(\mathrm{Fe}_{80} \mathrm{Si}_{6} \mathrm{~B}_{14}\right.$ and $\left.\mathrm{Fe}_{77} \mathrm{Si}_{8} \mathrm{~B}_{15}\right)$ crystallized without formation of the metastable $\mathrm{Fe}_{3} \mathrm{~B}$ phase whatever thermal treatment was applied. Taking into account that the metastable Fe-boride was found over the whole concentration range of binary $\mathrm{Fe}-\mathrm{B}$ metallic glasses upon crystallization [12], it is reasonable to suppose that the

a e-mail: i.kaban@ifw-dresden.de observed phenomena are related to the $\mathrm{Si}$ content in the Fe-Si-B ternary alloys. In [3] the crystallization kinetics of $\mathrm{Fe}_{90-\mathrm{x}} \mathrm{Si}_{\mathrm{x}} \mathrm{B}_{10}$ amorphous alloys was studied. It has been shown that the hypoeutectic glasses $(x<14)$ and hypereutectic glasses $(x>14)$ crystallize differently.

In the present work, a detailed investigation of the thermal-time treatment of two metallic glasses with constant $\mathrm{Fe}$ content and different $\mathrm{Si}-\mathrm{B}$ ratio $-\mathrm{Fe}_{82} \mathrm{Si}_{2} \mathrm{~B}_{16}$ and $\mathrm{Fe}_{82} \mathrm{Si}_{4} \mathrm{~B}_{14}$ - has been carried out.

\section{Experimental}

$\mathrm{Fe}_{82} \mathrm{Si}_{2} \mathrm{~B}_{16}$ and $\mathrm{Fe}_{82} \mathrm{Si}_{4} \mathrm{~B}_{14}$ amorphous ribbons were prepared from the precursor alloys by melt spinning, as described elsewhere $[2,12]$. Isothermal annealing of the amorphous ribbons has been carried under vacuum $\left(\sim 10^{-5}\right.$ mbar) in a furnace enabling fast heating to the desired temperatures.

X-ray diffraction experiments were performed with a standard DRON-3M diffractometer in $\theta-2 \theta$ geometry using monochromatic Mo $K_{\alpha}$ irradiation. The X-ray scattering intensity has been measured between $7^{\circ}$ and $90^{\circ}$ of $2 \theta$ in steps of $0.1^{\circ}$. The statistical error at the tail of the scattering curves did not exceed $1 \%$.

Thermal properties were investigated with a Perkin Elmer DSC-7 differential scanning calorimeter. The DSC measurements were carried out from room temperature up to $953 \mathrm{~K}$. The temperature and energy calibration of the device was performed using high purity metals supplied as standards. The temperature of the samples studied was measured with an accuracy of $\pm 0.1 \mathrm{~K}$. 


\section{Results and discussion}

Figure 1 shows the DSC curves obtained for $\mathrm{Fe}_{82} \mathrm{Si}_{2} \mathrm{~B}_{16}$ and $\mathrm{Fe}_{82} \mathrm{Si}_{4} \mathrm{~B}_{14}$ metallic glasses at a heating rate of 20 $\mathrm{K} / \mathrm{min}$. Substitution of 2 at.\% $\mathrm{Si}$ for B at the constant $\mathrm{Fe}$ content in the ternary $\mathrm{Fe}-\mathrm{Si}-\mathrm{B}$ alloys results in a remarkably different crystallization behaviour upon constant-rate heating. There is one exothermal signal with a peak at about $767 \mathrm{~K}$ in the DSC curve of the $\mathrm{Fe}_{82} \mathrm{Si}_{2} \mathrm{~B}_{16}$ amorphous alloy, while the DSC curve of the $\mathrm{Fe}_{82} \mathrm{Si}_{4} \mathrm{~B}_{14}$ metallic glass reflects two exothermal events with peaks at $756 \mathrm{~K}$ and $813 \mathrm{~K}$ (Fig. 1).

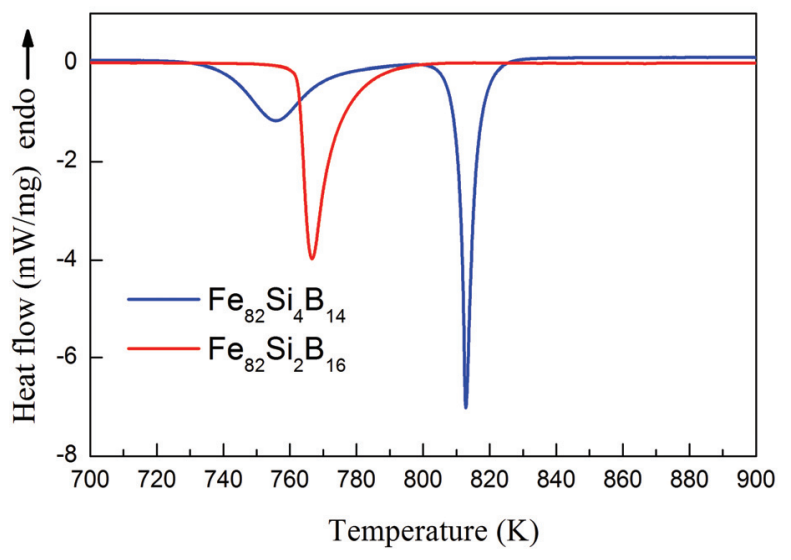

Fig. 1. DSC curves for the $\mathrm{Fe}_{82} \mathrm{Si}_{2} \mathrm{~B}_{16}[10]$ and $\mathrm{Fe}_{80} \mathrm{Si}_{6} \mathrm{~B}_{14}$ metallic glasses measured at a heating rate of $20 \mathrm{~K} / \mathrm{min}$.

Upon heating, the $\mathrm{Fe}_{82} \mathrm{Si}_{2} \mathrm{~B}_{16}$ alloy crystallizes with formation of the metastable $\mathrm{Fe}_{3} \mathrm{~B}$ phase. At first, crystals with b.c.c. structure (either $\alpha-(\mathrm{Fe}, \mathrm{Si})$ solid solution or $\alpha$ $\mathrm{Fe}$ and $\mathrm{Fe}_{3} \mathrm{Si}$ ) and $\mathrm{Fe}_{3} \mathrm{~B}$ phase appear; then, the metastable $\mathrm{Fe}_{3} \mathrm{~B}$ transforms into the stable $\mathrm{Fe}_{2} \mathrm{~B}$ and $\alpha-\mathrm{Fe}$ phases $[10,11]$. It has been shown that the $\mathrm{Fe}_{82} \mathrm{Si}_{2} \mathrm{~B}_{16}$ glass can also crystallize upon isothermal annealing at a temperature remarkably lower than the onset of nonisothermal crystallization: at $693 \mathrm{~K}$ against $733 \mathrm{~K}$ $[10,11]$. However, only reflexes of the b.c.c. crystalline phase $[\alpha-(\mathrm{Fe}, \mathrm{Si})]$ have been detected in the XRD patterns after 24 hours annealing in those works. One of the aims of the present study was to elucidate whether or not crystalline Fe-borides $\left(\mathrm{Fe}_{3} \mathrm{~B}, \mathrm{Fe}_{2} \mathrm{~B}\right)$ can precipitate at 693 $\mathrm{K}$ if the annealing is further prolonged.

In the present work, the $\mathrm{Fe}_{82} \mathrm{Si}_{2} \mathrm{~B}_{16}$ glass was annealed at $693 \mathrm{~K}$ for 24 hours. Then, the same sample was additionally heat-treated at $693 \mathrm{~K}$ for 11 hours. It is noteworthy that after the additional annealing, crystallites of a boride phase appeared indeed. However, this was already the stable $\mathrm{Fe}_{2} \mathrm{~B}$ phase. Distinct crystalline (110) and (202) reflexes characteristic of the stable $\mathrm{Fe}_{2} \mathrm{~B}$ phase are seen at about $11^{\circ}$ and $25^{\circ}$ in the XRD curve obtained after a total of 35 hours heat treatment (Fig. 2). Moreover, a weak increase of the intensity at the position of the reflexes of the $\mathrm{Fe}_{2} \mathrm{~B}$ phase has already been observed after annealing for 24 hours in our study.

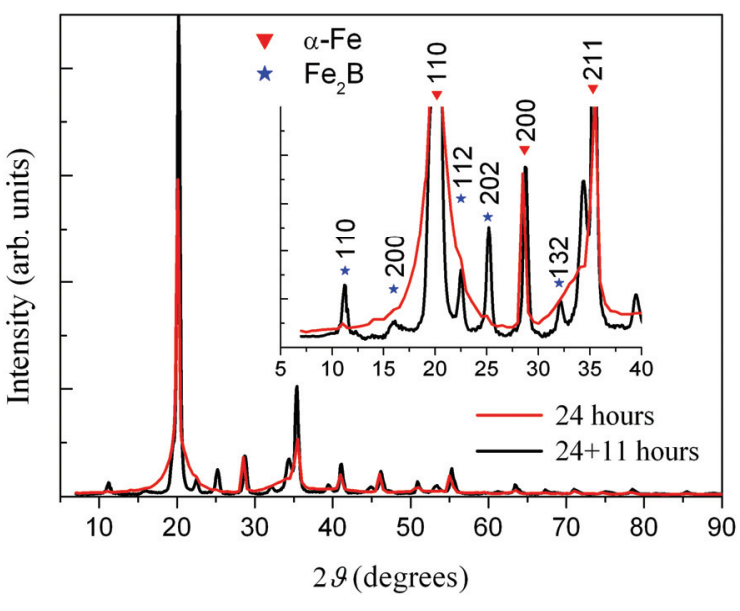

Fig. 2. XRD patterns for the $\mathrm{Fe}_{82} \mathrm{Si}_{2} \mathrm{~B}_{16}$ amorphous ribbon annealed at $693 \mathrm{~K}$ for 24 hours and after additional annealing for 11 hours.

Therefore, more detailed investigations of the $\mathrm{Fe}_{82} \mathrm{Si}_{2} \mathrm{~B}_{16}$ amorphous ribbons annealed from $15 \mathrm{~min}$ to 24 hours have been performed. The reflexes of b.c.c. $\alpha$ Fe crystallites are observed in the diffraction pattern after 3 hours of annealing (Fig. 3). The lines corresponding to borides start to appear after 15 hours of annealing. Mainly, these are reflexes of the stable boride $\mathrm{Fe}_{2} \mathrm{~B}$. Even if there are reflexes of the metastable $\mathrm{Fe}_{3} \mathrm{~B}$ phase visible, their intensity is very weak, obviously due to a small volume fraction of this phase.

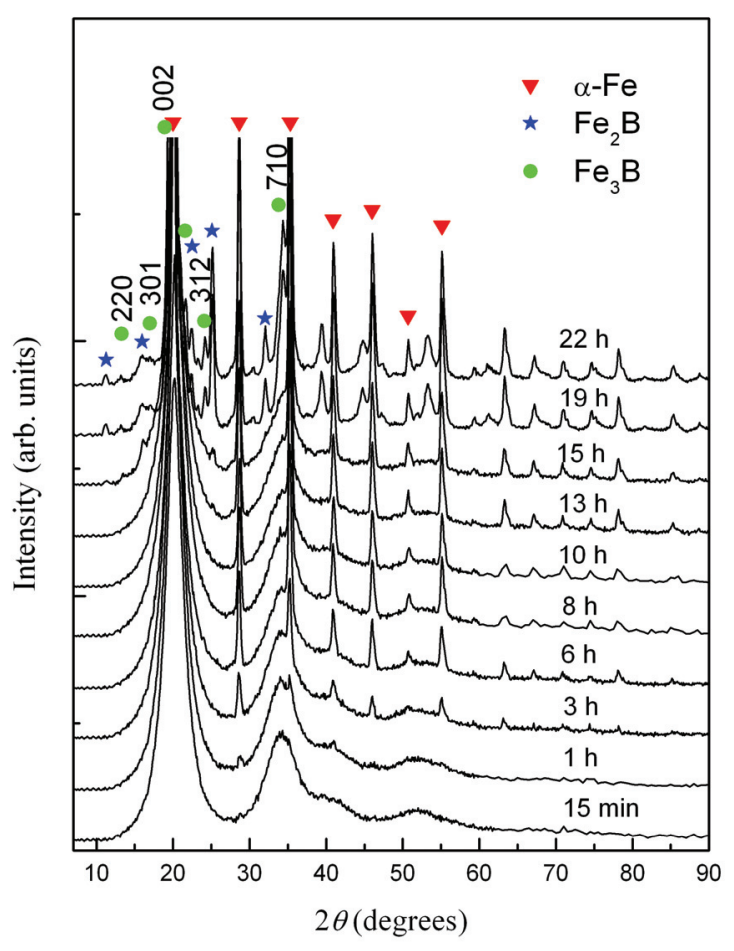

Fig. 3. XRD patterns of $\mathrm{Fe}_{82} \mathrm{Si}_{2} \mathrm{~B}_{16}$ amorphous ribbons annealed at $693 \mathrm{~K}$ for different time. 
Hence, our results confirm precipitation of the stable $\mathrm{Fe}_{2} \mathrm{~B}$ crystals upon annealing of the $\mathrm{Fe}_{82} \mathrm{Si}_{2} \mathrm{~B}_{16}$ metallic glass at a rather low temperature $(693 \mathrm{~K})$ if the annealing time is long enough. Considering this finding, one can suppose that the metastable boride $\mathrm{Fe}_{3} \mathrm{~B}$ formed in a $\mathrm{Fe}_{82} \mathrm{Si}_{2} \mathrm{~B}_{16}$ amorphous sample annealed at a higher temperature for a short time (i.e. after the first stage of crystallization) might transform into the stable $\mathrm{Fe}_{2} \mathrm{~B}$ phase by increasing the annealing time. Therefore, X-ray diffraction measurements of the $\mathrm{Fe}_{82} \mathrm{Si}_{2} \mathrm{~B}_{16}$ metallic glass annealed at $743 \mathrm{~K}$ for 1 to 24 hours have been performed.

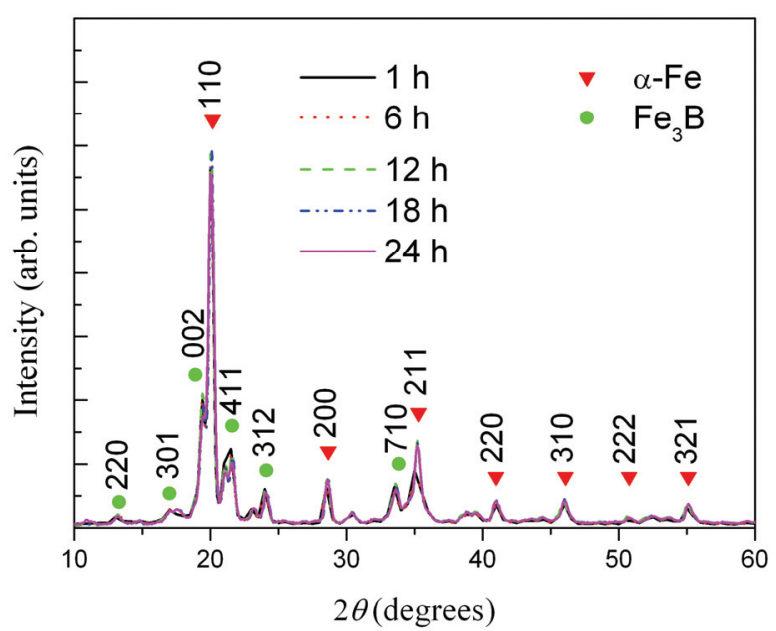

Fig. 4. XRD patterns for $\mathrm{Fe}_{82} \mathrm{Si}_{2} \mathrm{~B}_{16}$ metallic glass annealed at $743 \mathrm{~K}$ for different times.

However, despite the rather high annealing temperature (just $20 \mathrm{~K}$ below the position of the exothermic peak in the DSC curve, Fig. 1) and a long annealing time, the stable $\mathrm{Fe}_{2} \mathrm{~B}$ boride was not obtained. Only reflexes of the b.c.c. phase and reflexes of metastable $\mathrm{Fe}_{3} \mathrm{~B}$ are observed in the XRD patterns corresponding to different annealing times at $743 \mathrm{~K}$ (Fig. 4).

At a heating rate of $20 \mathrm{~K} / \mathrm{min}$, the $\mathrm{Fe}_{82} \mathrm{Si}_{4} \mathrm{~B}_{14}$ amorphous alloy starts to crystallize at about $723 \mathrm{~K}$ (Fig. 1). Therefore, similar to the $\mathrm{Fe}_{82} \mathrm{Si}_{2} \mathrm{~B}_{16}$ alloy, the $\mathrm{Fe}_{82} \mathrm{Si}_{4} \mathrm{~B}_{14}$ amorphous ribbons have been at first isothermally annealed at $693 \mathrm{~K}$ (Fig. 5). However, such annealing temperature turned out to be high for this composition. Already after $15 \mathrm{~min}$, the volume fraction of the b.c.c. crystalline phase was remarkable, and it was not possible to determine when this phase starts to precipitate. On the other hand, it was established that the stable $\mathrm{Fe}_{2} \mathrm{~B}$ phase appears already in the first stage of crystallization, i.e. without formation of the metastable boride $\mathrm{Fe}_{3} \mathrm{~B}$. In Fig. 5, (110) and (202) reflexes of the $\mathrm{Fe}_{2} \mathrm{~B}$ crystals are clearly visible in the XRD pattern recorded after 12 hours of isothermal annealing at 693 $\mathrm{K})$. It should be noted that the metastable $\mathrm{Fe}_{3} \mathrm{~B}$ phase has not been found for the $\mathrm{Fe}_{82} \mathrm{Si}_{4} \mathrm{~B}_{14}$ amorphous alloy whatever heat treatment was applied.

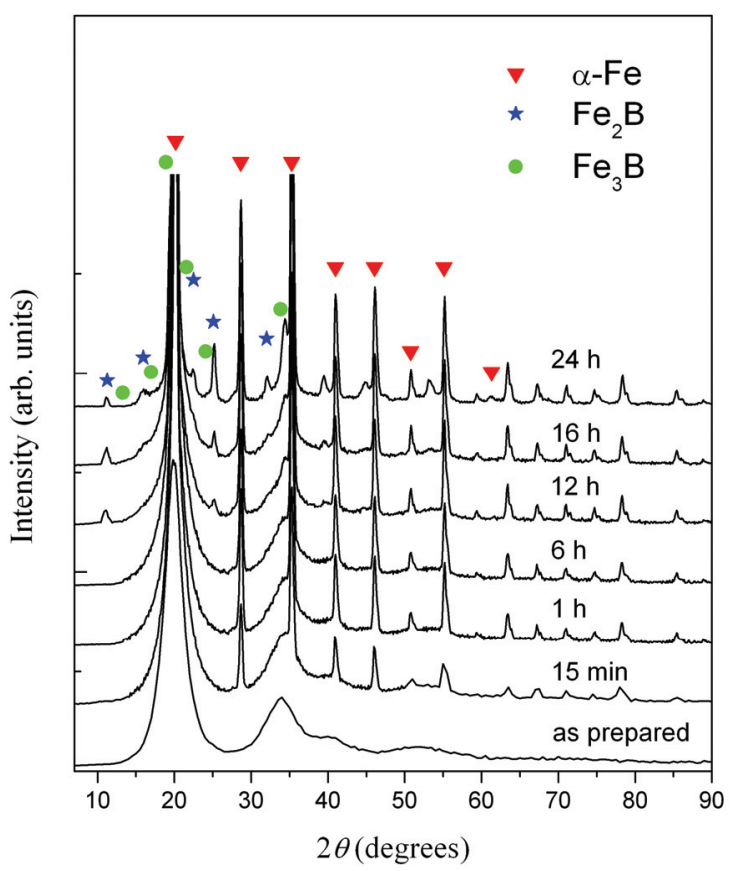

Fig. 5. XRD patterns for $\mathrm{Fe}_{82} \mathrm{Si}_{4} \mathrm{~B}_{14}$ metallic glass annealed at $693 \mathrm{~K}$ for different time.

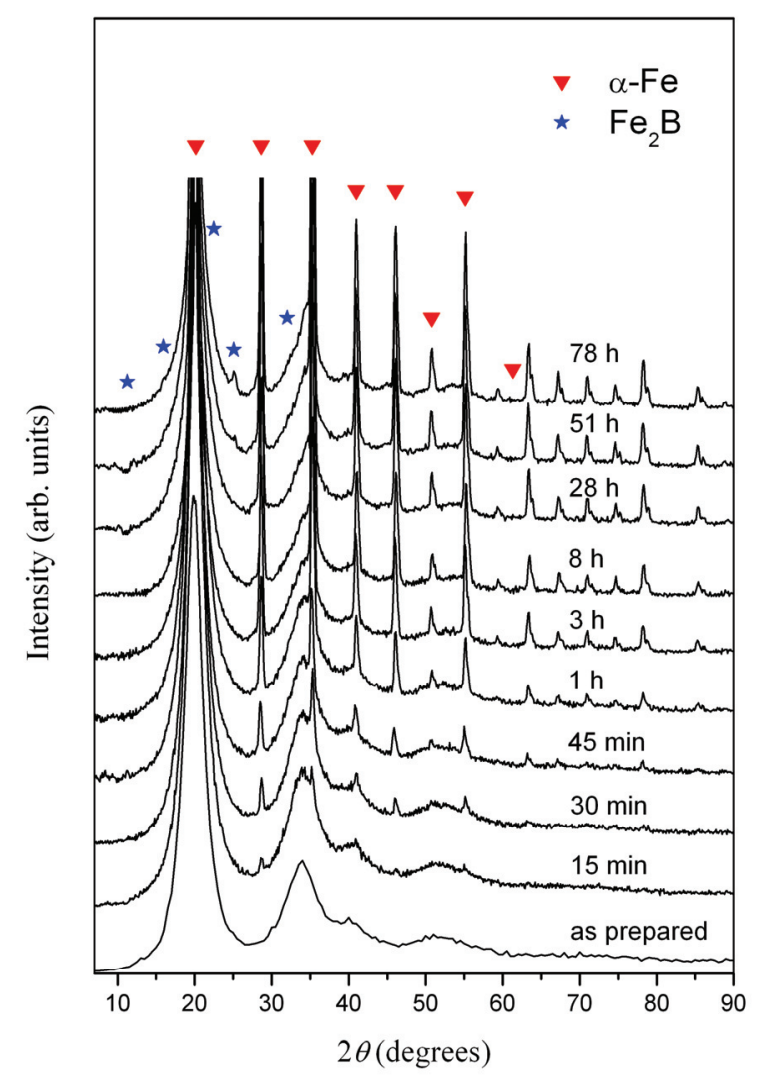

Fig. 6. XRD patterns for $\mathrm{Fe}_{82} \mathrm{Si}_{4} \mathrm{~B}_{14}$ metallic glass annealed at $673 \mathrm{~K}$ for different time. 
As we were not able to determine the start of the $\alpha$ (Fe,Si) precipitation at $693 \mathrm{~K}$, the annealing temperature was decreased to $673 \mathrm{~K}$. The XRD curves measured for the $\mathrm{Fe}_{82} \mathrm{Si}_{4} \mathrm{~B}_{14}$ amorphous ribbons after different annealing times at $673 \mathrm{~K}$ are plotted in Fig. 6. Also in this case, crystals of the b.c.c. phase started to appear after 15 min of heat treatment. However, their volume fraction was small. It is interesting that the decrease of the annealing temperature by $20 \mathrm{~K}$ slowed the nucleation rate of the Fe-boride significantly down. The reflexes corresponding to the $\mathrm{Fe}_{2} \mathrm{~B}$ phase have been observed in the XRD curves only after 51 hours of annealing, and even after an annealing time of 78 hours the volume fraction of the $\mathrm{Fe}_{2} \mathrm{~B}$ phase was rather small.

Both $\mathrm{Fe}_{82} \mathrm{Si}_{2} \mathrm{~B}_{16}$ and $\mathrm{Fe}_{82} \mathrm{Si}_{4} \mathrm{~B}_{14}$ amorphous alloys were also isothermally annealed at other temperatures between $673 \mathrm{~K}$ and $743 \mathrm{~K}$. No principal differences in the crystallization process from that described above have been found, only the crystallization rate was different. As an example, Fig. 7 shows two X-ray diffraction patterns for the $\mathrm{Fe}_{82} \mathrm{Si}_{4} \mathrm{~B}_{14}$ amorphous ribbons measured after isothermal annealing at $693 \mathrm{~K}$ for 6 hours and at $733 \mathrm{~K}$ for 1 hour. The coincidence of the XRD intensities demonstrates how the same final result (in this case, b.c.c. $\alpha-(\mathrm{Fe}, \mathrm{Si}))$ can be obtained by controlling the annealing time and temperature.

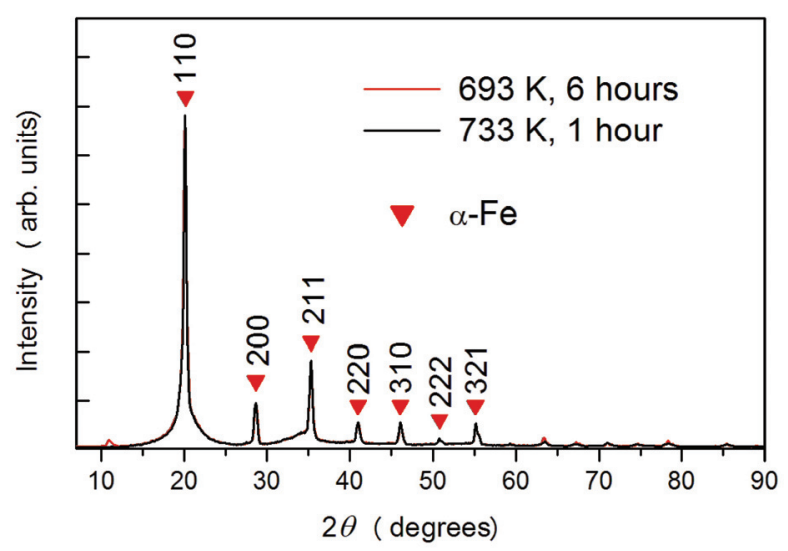

Fig. 7. XRD patterns for $\mathrm{Fe}_{82} \mathrm{Si}_{4} \mathrm{~B}_{14}$ metallic glass annealed at different temperatures and for different times.

\section{Conclusions}

In spite of rather close compositions, the $\mathrm{Fe}_{82} \mathrm{Si}_{2} \mathrm{~B}_{16}$ and $\mathrm{Fe}_{82} \mathrm{Si}_{4} \mathrm{~B}_{14}$ amorphous alloys crystallize in a different way. The DSC curve for $\mathrm{Fe}_{82} \mathrm{Si}_{2} \mathrm{~B}_{16}$ metallic glass exhibits only one exothermic maximum, while there are two exothermic peaks in the DSC curve for amorphous $\mathrm{Fe}_{82} \mathrm{Si}_{4} \mathrm{~B}_{14}$.

It is shown that the stable $\mathrm{Fe}_{2} \mathrm{~B}$ phase can be obtained already in the first stage of crystallization upon annealing $\mathrm{Fe}_{82} \mathrm{Si}_{2} \mathrm{~B}_{16}$ amorphous ribbons at $693 \mathrm{~K}$ if the annealing time is long enough.
If the metastable $\mathrm{Fe}_{3} \mathrm{~B}$ phase appeared after a short time heat treatment of amorphous $\mathrm{Fe}_{82} \mathrm{Si}_{2} \mathrm{~B}_{16}$, subsequent prolonged annealing at the same temperature did not result in a transformation from the metastable $\mathrm{Fe}_{3} \mathrm{~B}$ to the stable $\mathrm{Fe}_{2} \mathrm{~B}$ phase.

Upon annealing of the $\mathrm{Fe}_{82} \mathrm{Si}_{4} \mathrm{~B}_{14}$ amorphous alloy, the metastable $\mathrm{Fe}_{3} \mathrm{~B}$ phase was not found whatever heat treatment was applied.

\section{Acknowledgments}

O. Slukhovskyy acknowledges the Saxonian Ministry of Science and Art (SMWK) for the financial support of his stay at the IFW Dresden.

\section{References}

1. Y. Yoshizawa, S. Oguma, K. Yamauchi, J. Appl. Phys. 64, 6044 (1988)

2. V.K. Nosenko, V.V. Maslov, V.V. Kirilchuk, A.P Kochkubey, J. Phys.: Conf. Ser. 98, 072016 (2008)

3. W. Minor, B. Schönfeld, B. Lebech, B. Buras, W. Dmowski, J. Mater. Sci. 22, 4144 (1986)

4. S.G. Kim, N.E. Lee, H.Y. Ra, J. Cryst. Growth 92 , 629 (1988)

5. A.R. Bhatti, B. Cantor, J. Mater. Sci. 29, 816 (1994)

6. J. Kohlbrecher, A. Wiedemann, H. Wollenberger, N. Mattern, G. Goerigk, Nanostr. Mater. 6, 449 (1995)

7. E. Illekova, Thermochim. Acta 280-281, 289 (1996)

8. E. Illekova, F. Malizia, F. Ronconi. Thermochim. Acta 282-283, 91 (1996)

9. Y.R. Zhang, R.V. Ramanujan, Mater. Scie. Eng. A 416, 161 (2006)

10. A.G. Il'inskii, G.M. Zelins'kaya, V.V. Maslov, V.K. Nosenko, Yu.V. Lepeeva, Metallofizika I Noveishie Technologii 26, 1501 (2004)

11. A.P. Shpak, A.G. Il'inskii, G.M. Zelinskaya, Yu.V. Lepeeva, A.I. Dehktyar, Li Chengdong, Metallofizika I Noveishie Technologii 28, 1 (2006)

12. A.G. Il'inskii, V.V. Maslov, V.K. Nosenko, G.M. Zelinskaya, T.M. Khristenko, Li Chengdong, Metallofizika I Noveishie Technologii 28, 1369 (2006) 